\title{
The epidemiology and biology of pulmonary metastases
}

\author{
William D. Gerull, Varun Puri, Benjamin D. Kozower \\ Division of Cardiothoracic Surgery, Department of Surgery, Washington University, St. Louis, MO, USA \\ Contributions: (I) Conception and design: BD Kozower, WD Gerull; (II) Administrative support: None; (III) Provision of study materials or patients: \\ None; (IV) Collection and assembly of data: None; (V) Data analysis and interpretation: None; (VI) Manuscript writing: All authors; (VII) Final \\ approval of manuscript: All authors. \\ Correspondence to: Benjamin D. Kozower, MD, MPH. 660 S Euclid Ave, Campus Box 8234, St. Louis, MO, 63110, USA. Email: kozowerb@wustl.edu.
}

\begin{abstract}
Our goal in this chapter is to explore the complex processes of metastasis and why there is a predisposition for this to occur in the lung. In addition, we aim to describe the incidence of pulmonary metastases in various contexts and based on the origin of the primary tumor. There are unique characteristics of the pulmonary system that make metastases more likely to occur in the lung than anywhere else in the body. Some of these characteristics include receiving the entire cardiac output every minute, having the densest capillary bed in the body, and being the first reservoir of most lymphatic drainage entering the venous system. There are multiple postulated routes of metastasis to the pulmonary system including hematogenous and lymphatic routes with early or late dissemination. The vascularization of pulmonary metastases is variable and complex, often recruiting supply from bronchial and pulmonary origin. There are also many biochemical factors in the tumor microenvironment that play a key role in the development of lung metastases including vascular endothelial growth factor (VEGF), interleukin-8 (IL-8), very late antigen 4 (VLA-4) and intercellular adhesion molecule 1 (ICAM-1). Studies vary widely in reported rates of pulmonary metastases due to differences in clinical study design, however, it is commonly accepted that up to half of autopsies performed on patients who died of malignancy have pulmonary metastases. In a surgical series describing the incidence of primary cancer types with resected pulmonary metastases the most common sites were thyroid, colon, breast, genitourinary tract, skin, liver, breast, and adrenal glands.
\end{abstract}

Keywords: Lung; metastases; metastasis

Submitted Nov 22, 2019. Accepted for publication Mar 19, 2020.

doi: $10.21037 /$ jtd.2020.04.28

View this article at: http://dx.doi.org/10.21037/jtd.2020.04.28

\section{Introduction}

Pulmonary metastases are a common occurrence in patients with extrathoracic cancer. Our goal in this chapter is to explore the complex processes of metastasis and why there is a predisposition for this to occur in the lung. In addition, we aim to describe the incidence of pulmonary metastases in various contexts and based on the origin of the primary tumor.

\section{Pathophysiology}

The process of metastatic spread involves many complex events. The pathophysiology of pulmonary metastasis is initiated with the growth, neovascularization, and tissue invasion of the primary tumor. Subsequently, there is detachment of cells from the primary tumor and hematogenous dissemination where these cells may arrest and proliferate in capillary beds. After surviving host defense mechanisms, the tumor cells extravasate into larger arteries and extend into organs by adhering to the basement membrane (1). There are many host-factors that must act in concert for this process to occur, including cell adhesion molecules, motility, growth and angiogenesis factors and various cytokines $(2,3)$.

There are unique characteristics of the pulmonary system that make metastases more likely to occur in the lung than anywhere else in the body. Schueller et al. describe these 
features well, "The lungs receive the entire cardiac output every minute. They also have the densest capillary bed in the body and are the first capillary plexus that most of the lymphatic drainage meets after entering the venous system. In addition, the lungs consist of a meshwork of delicate membranes that easily entrap tumor cells which can readily draw on nearby oxygenated air for sustenance." (4). These characteristics provide an ideal situation and environment for the cascade of events to occur that lead to metastases in the lung. The rate of growth of metastases was studied by Spratt et al. They performed a radiographic study of 118 patients with untreated pulmonary metastases and demonstrated, through mathematical calculation and radiographic correlation, that the rate of growth of the pulmonary metastases was exponential (5).

There are multiple routes of metastasis to the lung from extra thoracic tumors. Certain groups of extrathoracic tumors have characteristic patterns of spread attributed to the unique and complex series of events that must occur for metastasis to succeed. The most common route of metastasis is a hematogenous mechanism. This pattern of spread is first initiated with detachment of cells from the primary tumor and hematogenous dissemination of the cells into pulmonary capillary beds. A minority of these cells will survive host defense mechanisms and penetrate the pulmonary interstitium, leading to metastatic growth (6). It is also possible for the pulmonary vasculature to be seeded at the same time as dissemination in other capillary beds such as the liver, bone or brain. In addition, there are situations where hematogenous spread occurs only after other capillary beds have been seeded, such as prostate or breast cancer. Metastatic spread can also occur via lymphatic channels-regional lymph nodes become the site of collection, which commonly occurs with endobronchial metastases (7).

As previously described, pulmonary metastasis is a complex process of tumor cell dissemination from the primary tumor to the lungs. There are currently two major concepts of metastasis that may influence the approach of clinicians (8). Fidler et al. describes a theory of late dissemination of metastases. This is postulated to occur after genetic changes to the primary tumor and surrounding environment have occurred that are sufficient for migration and spread (9). A different theory suggests metastasis occurs via early dissemination. Morgan et al. describes a process of early shedding of single cancer cells. There is a subsequent dormant stage where the cells may acquire genetic and environmental alterations that trigger proper metastasis and lead to delayed recurrence (10). Both theories of metastasis may occur separately or together within different tumor types and individuals-rendering the genetic composition and characteristics of pulmonary metastases unique and complex to treat.

For lung metastases to grow, adequate nutrition is needed via a viable blood supply. In the lung, there are three possible routes: bronchial circulation, pulmonary circulation, or both. The route of blood supply to the metastases is important as it can be a means of therapeutic intervention. Historically, it was held that most lung tumors are supplied by bronchial circulation and that pulmonary "neovascularization" did not occur (11-13). However, Milne et al. conducted a computer topographic angiography study of resected human lungs with pulmonary metastases of varying origin which demonstrated that angiogenesis does occur. In addition, there was a pulmonary circulation component in all metastases usually supplying the lateral portion of the tumor (14). The vascularization of pulmonary metastases is variable and complex, often recruiting supply from bronchial and pulmonary origin.

Interestingly, diet may also have a role in tumor growth. Hayman et al. details a study that has shown how a diet high in omega- 6 fatty acids has been linked to statistically higher rates of visible lung metastases in mice injected with human breast cancer cells. As well, omega-3 fatty acids have been shown to reduce lung metastases in colorectal cancer, breast carcinoma, and melanoma (15). This is postulated to be due to influences on gene expression which can affect the production of various protein factors.

There are many biochemical factors in the tumor microenvironment that play a key role in the development of lung metastases. Laboratory studies have shown that cellular factors such as vascular endothelial growth factor (VEGF), interleukin-8 (IL-8), platelet-derived endothelial cell growth factor (PD-ECGF), and/or basic fibroblast growth factor (bFGF) play an important role in the tumor microenvironment (16). As well, tumor cells have a role in metastatic invasion with very late antigen 4 (VLA-4) production from hematopoietic progenitor cells. This production of VLA-4 allows for interaction with fibronectin in fibroblasts at premetastatic sites (17). Chemokines are activated by tumor cells through the attraction of immune cells and tumor cells to the lungs via VEGF-A, tumor necrosis factor- $\alpha(\mathrm{TNF}-\alpha)$, and transforming growth factor$\beta$ (TGF- $\beta$ ) inducing expression of inflammatory chemokines used for lung invasion (18). Once tumor cells are at the site of metastasis, they can anchor to the environment through 
Table 1 Incidence and cumulative incidence of pulmonary metastases ${ }^{\circ}$ in various non-pulmonary cancer type

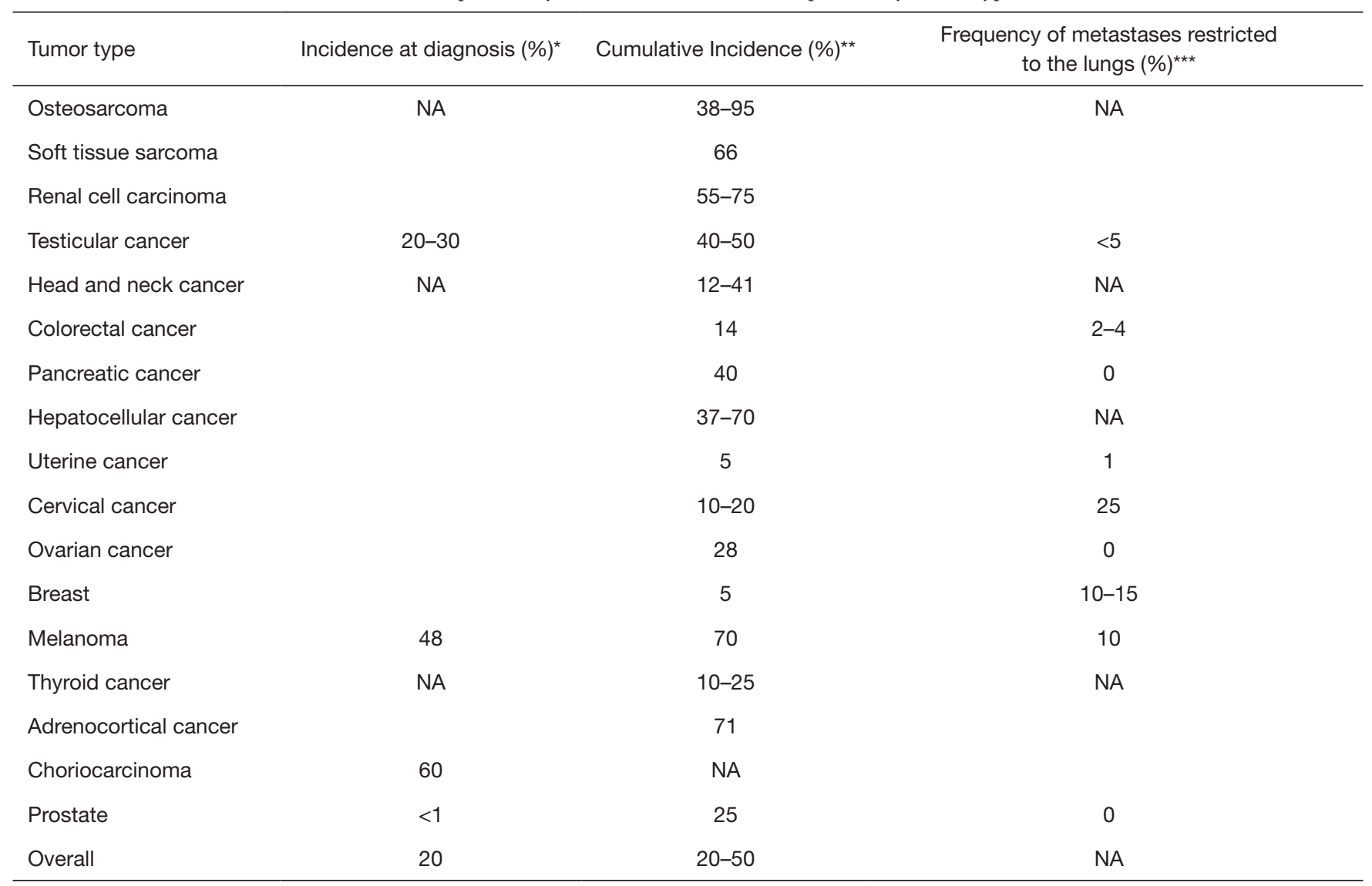

${ }^{\circ}$, pulmonary parenchymal metastases; ${ }^{*}$, expressed as percentage of patients presenting with the specific tumor type; ${ }^{*}$, expressed as percentage of patients with the specific tumor type; ${ }^{\star \star *}$, expressed as percentage of patients with metastases restricted to the lung (without metastases elsewhere).

surface expression of intercellular adhesion molecule 1 (ICAM-1) induced be recruited neutrophils (19). Cellular expression of proteins that enhance anchoring, recruitment of cells and invasion are necessary for lung metastasis.

\section{Epidemiology}

The lung is the most common site for cancer metastases. In addition, that most common malignant tumors found in the lung are metastases from extrathoracic tumors $(4,20)$. Studies vary widely in reported rates of pulmonary metastases due to differences in clinical study design such as tumor type, the time period from primary tumor to pulmonary metastases, and the type and frequency of imaging used to detect them. This time period can be significant as it has been shown that pulmonary metastases have been described up to 15 years after primary cancer detection (6). It is commonly accepted that up to half of autopsies performed on patients who died of malignancy have pulmonary metastases $(21,22)$. Regardless of the high amount of reported lung metastases in patients with cancer, only $15 \%$ to $20 \%$ develop clinical symptoms such as cough or nonspecific chest pain from metastases (15). Van Meerbeeck et al. combined data from multiple autopsy series to describe the cumulative incidence of pulmonary metastases for non-pulmonary types of cancer (Table 1) (23). This shows a high incidence in urogenital and intestinal origin likely due to the cancer distribution of the population. Detterbeck et al. conducted a surgical series of 6,732 patients describing the incidence of primary cancer types with resected pulmonary metastases (Table 2) (24). These resected metastases were presumed "solitary" or "unique" by available staging techniques and reflect a more clinically meaningful distribution of identified 
Table 2 Distribution of primary cancer types in patients with resected pulmonary metastases in a surgical series of 6,732 patients

\begin{tabular}{lc}
\hline Primary cancer type & Distribution (\%) \\
\hline Sarcoma & 36 \\
Teratoma & $3-37$ \\
Head and neck cancer & $5-24$ \\
Colon cancer & 10 \\
Breast cancer & 9 \\
Genito-urinary cancer & 9 \\
Melanoma & 4 \\
Gyncecological cancer & 4 \\
\hline
\end{tabular}

pulmonary metastases. The most common sites were thyroid, colon, breast, genitourinary tract, skin, liver, breast, and adrenal glands. However, this study was biased due to "resectability"-pulmonary metastases from colon cancer may be resectable whereas systemic spread of prostate cancer is usually unresectable and therefore not reflected in this study. In summary, there are multiple ways to describe the incidence of pulmonary metastases, which varies due to clinical definition and the population studied.

\section{Acknowledgments}

Funding: None.

\section{Footnote}

Provenance and Peer Review: This article was commissioned by the Guest Editor (Khosro Hekmat) for the series "Pulmonary Metastases" published in fournal of Thoracic Disease. The article has undergone external peer review.

Conflicts of Interest: All authors have completed the ICMJE uniform disclosure form (available at: http://dx.doi. org/10.21037/jtd.2020.04.28). The series "Pulmonary Metastases" was commissioned by the editorial office without any funding or sponsorship. The authors have no other conflicts of interest to declare.

Ethical Statement: The authors are accountable for all aspects of the work in ensuring that questions related to the accuracy or integrity of any part of the work are appropriately investigated and resolved.
Open Access Statement: This is an Open Access article distributed in accordance with the Creative Commons Attribution-NonCommercial-NoDerivs 4.0 International License (CC BY-NC-ND 4.0), which permits the noncommercial replication and distribution of the article with the strict proviso that no changes or edits are made and the original work is properly cited (including links to both the formal publication through the relevant DOI and the license). See: https://creativecommons.org/licenses/by-nc-nd/4.0/.

\section{References}

1. Ito H, Nakayama H. Surgical management of pulmonary metastases. Gan To Kagaku Ryoho 2010;37:200-3.

2. Snyder BJ, Pugatch RD. Imaging characteristics of metastatic disease to the chest. Chest Surg Clin N Am 1998;8:29-48.

3. Yoneda KY, Louie S, Shelton DK. Approach to pulmonary metastases. Curr Opin Pulm Med 2000;6:356-63.

4. Schueller G, Herold CJ. Lung metastases. Cancer Imaging 2003;3:126-8.

5. Spratt JS, Spratt TL. Rates of Growth of Pulmonary Metastases and Host Survival. Ann Surg 1964;159:161-71.

6. Watanabe A. Cancer metastases research. Nova Science Publishers,2008:215-35.

7. Filderman AE, Coppage L, Shaw C, et al. Pulmonary and pleural manifestations of extrathoracic malignancies. Clin Chest Med 1989;10:747-807.

8. Gonzalez M, Krueger T, Perentes JY. Pulmonary Metastasis. In: Introduction to Cancer Metastasis. Elsevier Inc, 2016:297-315.

9. Fidler IJ. The pathogenesis of cancer metastasis: the 'seed and soil' hypothesis revisited. Nat Rev Cancer 2003;3:453-8.

10. Morgan TM, Lange PH, Porter MP, et al. Disseminated tumor cells in prostate cancer patients after radical prostatectomy and without evidence of disease predicts biochemical recurrence. Clin Cancer Res 2009;15:677-83.

11. Boijsen E, Zsigmond M. Selective angiography of bronchial and intercostal arteries. Acta Radiol Diagn (Stockh) 1965;3:513-28.

12. Noonan CD, Margulis AR, Wright R. Bronchial Arterial Patterns in Pulmonary Metastasis. Radiology 1965;84:1033-42.

13. Newton TH, Preger L. Selective Bronchial Arteriography. Radiology 1965;84:1043-51.

14. Milne ENC, Zerhouni EA. Blood supply of pulmonary metastases. J Thorac Imaging 1987;2:15-23. 
15. Hayman J, Naidoo J, Ettinger DS. Lung Metastases. In: Niederhuber JE, Armitage JO, Doroshow JH, et al. editors. 6th edition. Abeloff's clinical oncology 2020:831-46.

16. Duda DG, Duyverman AMMJ, Kohno M, et al. Malignant cells facilitate lung metastasis by bringing their own soil. Proc Natl Acad Sci U S A 2010;107:21677-82.

17. Kaplan RN, Riba RD, Zacharoulis S, et al. VEGFR1positive haematopoietic bone marrow progenitors initiate the pre-metastatic niche. Nature 2005;438:820-7.

18. Hiratsuka S, Watanabe A, Aburatani H, et al. Tumourmediated upregulation of chemoattractants and recruitment of myeloid cells predetermines lung metastasis. Nat Cell Biol 2006;8:1369-75.

19. Huh SJ, Liang S, Sharma A, et al. Transiently entrapped circulating tumor cells interact with neutrophils to facilitate lung metastasis development. Cancer Res 2010;70:6071-82.

Cite this article as: Gerull WD, Puri V, Kozower BD. The epidemiology and biology of pulmonary metastases. J Thorac Dis 2021;13(4):2585-2589. doi: $10.21037 /$ jtd.2020.04.28
20. Crow J, Slavin G, Kreel L. Pulmonary metastasis: a pathologic and radiologic study. Cancer 1981;47:2595-602.

21. Hirakata K, Nakata H, Nakagawa T. CT of pulmonary metastases with pathological correlation. Semin Ultrasound CT MR 1995;16:379-94.

22. Putnam JB. New and evolving treatment methods for pulmonary metastases. Semin Thorac Cardiovasc Surg 2002;14:49-56.

23. Van Meerbeeck JP, Gosselin R, Duyck P. Lung Metastases: Epidemiology, Clinical Presentation and Imaging. In: Schil PV. editor. Lung Metastases and Isolated Lung Perfusion. Nova Science Publishers, 2007:3-25.

24. Detterbeck FC, Sadoff JD. Pulmonary metastases from extrapulmonary cancer. In: Detterbeck FC, Rivera MP, Socinski M, et al. Diagnosis and treatment of lung cancer An evidence-based guide for the practicing clinician. Philadelphia: WB Saunder, 2001:450-64. 